\title{
A case for re-establishment of cardiac surgery at Chris Hani Baragwanath Academic Hospital, South Africa
}

Chris Hani Baragwanath Academic Hospital, popularly known as Bara, was built by the Imperial government in 1940 to cater for British and Allied soldiers from the Eastern Frontier war on land owned by a Cornish immigrant, Mr John Albert Baragwanath. ${ }^{[1]}$ In 1947, it was turned into a 480-bed civilian hospital for the new inhabitants of Soweto, forcibly relocated from Sophiatown. ${ }^{[1]}$ As Soweto grew to become one of the largest townships on the continent, so too did Bara grow to become the third-largest hospital in the world, with 2800 beds. It also became the largest teaching platform for medical students of the University of the Witwatersrand.

In 1940, Coronation Hospital was turned into a 400-bed hospital for non-Europeans with all services rendered there. The nearby Princess Alice Hospital was merged with Coronation Hospital (now Rahima Moosa Mother and Child Hospital). However, its close proximity to Sophiatown, within the city of Johannesburg, meant that black Africans would still use Coronation for their healthcare needs, thereby negating the grand apartheid plan. In 1947, Bara was taken over by the Transvaal Provincial Administration and expanded into a 900-bed hospital. At least the 'natives' would have a hospital in their new home of Soweto nearby. Accordingly, all surgical disciplines including cardiac surgery were made available at Bara.

The Division of Cardiology at Bara is the busiest in South Africa (SA), as it provides a tertiary cardiology service to southern Gauteng Province, North West, parts of Northern Cape, and informally the rest of SA bar the Western Cape. Because of its 'inadvertently liberal admission policy', with no red-tape-driven exclusions, Bara is also the major point of care for immigrants from Bangladesh, the Democratic Republic of the Congo, Malawi, Mozambique, Pakistan, Zimbabwe, Somalia and other countries. Adults and children from these drainage areas with acute cardiac emergencies or complex cardiac conditions are referred to Bara for management, including surgery. Unfortunately, cardiac surgery has not been available at Bara since 1998. In the early 1980s, Bara, together with the then J G Strydom Hospital (now Helen Joseph), provided world-class cardiac surgical services, performing over 1000 open-heart procedures annually. It also trained some internationally acknowledged surgeons, including Emeritus Professor Antunes of the University of Coimbra in Portugal, whose departure from SA in 1998 ended cardiac surgery at Bara. However, the need for cardiac surgery never abated owing to old epidemics of chronic rheumatic heart diseases (RHDs), ${ }^{[2]}$ endocarditis (subacute bacterial endocarditis, SBE), adult congenital, and the new epidemic of ischaemic heart disease. ${ }^{[2,3]}$ Furthermore, excellent clinical cardiology services offered at Bara, including cardiac magnetic resonance imaging, 3D-echocardiography and coronary computed tomography angiography, improve screening and rapid identification of patients requiring surgery, while complications arising from the performance of complex coronary interventions and electrophysiological ablation may necessitate the need for emergency cardiac surgery.

Until now, Bara patients could only access cardiac surgery at Charlotte Maxeke Johannesburg Academic Hospital (CMJAH), $20 \mathrm{~km}$ away. Indeed, $60-70 \%$ of cardiac patients operated on at $\mathrm{CMJAH}$ were referrals from Bara, an anomaly, as service ought to be available where the bulk of the patients are. Recently, fire destroyed parts of CMJAH, necessitating its immediate prolonged closure.
The cardiac surgical intensive care unit (ICU) and its theatres were affected. Currently, Bara patients can only access cardiac surgery once weekly at Steve Biko Hospital (SBH) in Pretoria, 72 km away, a trickle given the magnitude of the need.

The unavailability of cardiac surgery at Bara confers a survival disadvantage to unstable patients, as they are transported out to another hospital in an ICU ambulance, not readily available in the public sector. The inherent surgical delay inevitably results in some patients developing multi-organ failure, and in preventable death. ${ }^{[4-6]}$ Indeed, all the patients who were transferred to SBH during the first 2 weeks of closure of CMJAH had complications on arrival, with high mortality. It would therefore be more sensible to re-establish cardiac surgery at Bara.

Early operation shortens patients' ICU and hospital stays, and improves survival. ${ }^{[5]}$ Many patients from Baragwanath Hospital who require cardiac surgery are young adults who go on to lead productive lives. ${ }^{[7]}$ The cost saving to the state of a breadwinner saved from premature cardiovascular death is immeasurable, as such individuals go on to provide for their families, who do not have to rely on social grants. After all, what better repayment is there to these real victims of apartheid than to ensure that their hearts are mended so that they get a second chance in life?

The raging RHD epidemics and the escalating incidence of SBE, now also driven by frustrated unemployed youth resorting to a new cheap intravenous drug, 'nyaope, ${ }^{[8]}$ should serve as a wake-up call to health authorities that the need for cardiac surgical services at Bara will continue to exist. The majority of these patients live in informal settlement areas without access to basic services. The COVID-19 pandemic has strained healthcare facilities, including Bara. Additionally, poor maintenance of our city infrastructure due to 'state capture' ${ }^{[9]}$ has not spared our hospitals. The fire at CMJAH led to overnight closure of a 1200 -bed inner-city hospital, taking with it what little access to cardiac surgery was available to the increasing numbers of patients at Bara, who now without an alternative are left with the possibility of prematurely confronting their ultimate fate, leaving those dependent on them without support.

\section{R Nethononda}

Division of Cardiology, Chris Hani Baragwanath Academic Hospital, Johannesburg, South Africa

mashudu.nethononda@wits.ac.za

\section{Sussman}

Netcare Milpark Private Hospital, Johannesburg, South Africa

\section{S M Mogaladi}

Department of Cardiothoracic Surgery, Charlotte Maxeke Johannesburg Academic Hospital, Johannesburg, South Africa

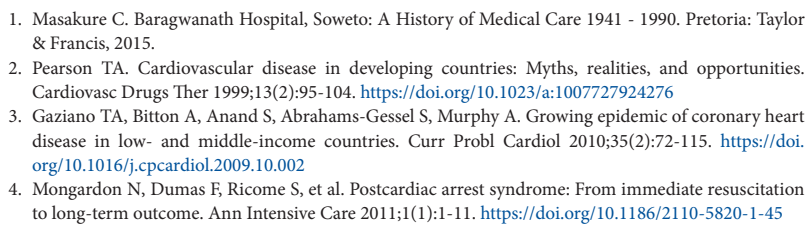


5. Montrief T, Koyfman A, Long B. Coronary artery bypass graft surgery complications: A review for emergency clinicians. Am J Emerg Med 2018;36(12):2289-2297. https://doi.org/10.1016/j. ajem.2018.09.014

6. Hochman IS, Buller CE, Sleeper LA, et al. Cardiogenic shock complicating acute myocardial infarctionetiologies, management and outcome: A report from the SHOCK Trial Registry. J Am Coll Cardiol 2000;36(3S1):1063-1070. https://doi.org/10.1016/s0735-1097(00)00879-2

7. Marcus RH, Sareli P, Pocock WA, Barlow JB. The spectrum of severe rheumatic mitral valve disease in a developing country: Correlations among clinical presentation, surgical pathologic findings, and hemodynamic sequelae. Ann Intern Med 1994;120(3):177-183. https://doi.org/10.7326/0003-4819-120 3-199402010-00001
8. Essop M, Peters F, Meel R. Tricuspid valve endocarditis associated with intravenous nyoape use: A report of 3 cases. Afr J Health Professions Educ 2014;104(12):853-855. https://doi.org/10.7196/SAMJ.8291

9. Martin ME, Solomon H. Understanding the phenomenon of 'State capture' in South Africa. Southern African Peace and Security Studies 2016;5(1):21-34. http://www.saccps.org/pdf/5-1/5-1_DRMartin_ African Peace and Security Studies 2016;5(1):2 